\title{
Health Related Quality of Life Questionnaires: Are They Fit for Purpose?
}

\author{
Kate Reid ${ }^{1,2}$, Derek Farrell ${ }^{2}$ and Carol Dealey ${ }^{1,2}$ \\ ${ }^{1}$ University Hospital Birmingham NHS Foundation Trust \\ ${ }^{2}$ University of Birmingham \\ United Kingdom
}

\section{Introduction}

Patients frequently ask two poignant questions during their management: 'how will I be after my treatment?' and 'am I cured?' Focused or absolute answers are generally frustratingly absent and the multidisciplinary team are likely to be guarded in their response because at presentation the site of the tumour and the stage of the disease will influence treatment possibilities and outcome. Outcome from the varying treatment modalities have been reported in terms of survival-interval and more recently the patients' quality of life (QoL). The latter outcome is a multifaceted and dynamic concept which the World Health Organisation defined as a: "broad ranging concept affected in a complex way by a person's physical health, psychological state, level of independence and their relationships to salient features of their environment" (WHOQOL group, 1993). More specifically such data in the context of disease is described in terms of health-related QOL (HRQoL) the subjective experience of the impact of health status on QoL for the patient (Curtis, 1997;) and can in relation to H\&NC patients be described as a patient's physical, emotional and social function at the pre and post-treatment stage(Hammerlid et al., 2001, Hammerlid and Taft, 2001).

The number of studies that routinely report on HRQoL has increased substantially over the last twenty years. In the literature it has been recommended that HRQoL tools should not only be used within the research arena but also within the clinical-setting (Velikova et al 2010). However the recommendation has not been put into practice and their use within the clinical setting remains limited. It would seem that clinicians have a poor understanding of what is available and are not able to link the findings with the clinical reality in which they work. This is despite patients reporting them both as a useful way of structuring their thoughts during outpatient appointments as well as a way of building a rapport with the teams involved in their care (Mehanna and Morton, 2006a, Velikova et al., 2010). Researchers have investigated why clinicians do not use QoL measures routinely within the clinical environment (Mehanna and Morton, 2006b, Kanatas et al., 2009). The results have suggested that clinicians do not view the findings as relevant to the clinical setting and that the logistical burden in the resultant collection and analysis of the data is too great. The volume of QoL questionnaires to choose from further complicates the situation. In a review of the head and neck cancer (H\&NC) literature Kanatas and Rogers (2008) identified five 
broad categories of patient completed QoL questionnaires and as many as thirteen diseasespecific questionnaires. Their conclusion was similar to a previous review by Ringash and Bezjak (2001) in which it was acknowledged that choice of questionnaire should be governed by the research questions being considered and the resources available.

The use of QoL data acknowledges that the patient aspect should be represented and that this information should be collected from the patient rather than from other sources such as health care professionals or carers, the former are likely to over estimate the physical symptoms (Reid et al., 2009) the latter under estimate the emotional aspects of the disease (Sollner et al., 2001). Complexity exists in all aspects of the field from the choice of questionnaire available to the possible influences on the results. Many and diverse variables would appear to impact on QoL scores and these include psycho-social factors: tumour characteristics,(Hammerlid et al., 2001) physical symptoms, (Campbell et al., 2004) treatments undergone,(Department of Health, 2011, Ronis et al., 2008) as well as psychosocial aspects of patients(Llewellyn et al., 2005, Howren et al., 2010).

The multi-dimensional and subjective nature of QoL makes it difficult to fit into the biomedical model throughout the treatment management process. The link between QoL scores and survival for this group of patients has been noted to be neither strong nor proven (Mehanna et al., 2008). Over time the scores within categories or sub-categories might vary without an apparent change to the overall score, or the possibility that if scores do change they are often in relation to the patent's emotional response to a life-changing event and not as a consequence of a shift in physical symptoms. It is therefore very possible that scores are more a reflection of people's adjustment to their change of circumstances rather than a measure of their physical or emotional state. This notion has been demonstrated by a study by Logemann et al (Logemann et al., 2001) in which the impact of dry mouth on H\&NC patients' function and perception of their swallow was investigated post radiotherapy. Logemann et al concluded that dry mouth did impact on sensory and comfort issues of swallowing but not on the actual function of the swallow. This would suggest that the patients are moderating or adjusting to the experience and that whilst objective measures are important there is value in collecting the diverse subjective aspects because this will influence patients' score to physical aspects of the disease or treatment. A systematic review of the HRQoL, for H\&NC patients diagnosed and treated with reference to psychosocial variables Llewellyn et al (Llewellyn et al., 2005) suggested that personality, depressive symptoms, social support, satisfaction with consultation and information, consumption of alcohol and tobacco all influenced HRQoL scores. In the same year a study carried out by Scharloo et al (Scharloo et al., 2005) described how illness perceptions by patients -attention to symptoms, believing in a greater likelihood of recurrence, engaging in self-blame, and a strong emotional reaction to the illness- all contributed to lower QoL scores. There are therefore indications that the impact of the disease and treatment is moderated by subjective patient characteristics. A review of the QoL within the field of H\&NC by Montazeri (Montazeri, 2009) identified eight papers that reviewed QoL and survival. Whilst four of the papers were not conclusive in their findings about the effect of QoL on survival a further four did show a clear relationship in areas such as cognitive function, (de Graeff et al., 2001) pain, appetite and eating scores (Karvonen-Gutierrez et al., 2008) and pre-treatment fatigue (Karvonen-Gutierrez et al., 2008, Fang et al., 2004) were reported as being linked to survival. 
The conclusion of the review paper was that in order to really identify other variables more methodological and statistical rigor should be used in future studies. This recommendation is a recurring conclusion and perpetuates the concept that quantitative research is an adequate way of investigating the clinical complexity evident within the specialty H\&NC. Such an approach holds with the belief that if homogeneity can be achieved between patient-groups eventually statistically significant variables can be identified. Perhaps this is currently an unrealistic goal with the instruments available and explains why different studies might appear to contradict one another. It is therefore possible that the actual variables that truly impact on outcome as measured by QoL remain both multiple, illusive and therefore uncertain.

It would be a limiting concept to suggest that H\&NC impacts on the physical aspects of a patient with no influence on the emotional aspect. It would also be too simplistic to suggest that patients do not draw upon previous life events in order to help them mange the current diagnosis. From these two premises there is value in exploring the experience of H\&NC at an individual level. The National Institute for Clinical Excellence estimates that $50 \%$ of all patients experience anxiety or depression at some point during their cancer assessment treatment and recovery (National Institue for Clinical Excellence, 2004). If the subjective aspect is left out in an attempt to follow a quantitative approach to study design the relevance of the results will remain, from the clinical perspective, poor representations of the patients. This will mean that clinicians fail to perceive a link between making clinical decisions and the research because it poorly depicts their caseload.

Being able to describe in a more representative way the disease and treatment is the preliminary stage of patient management. A United Kingdom government report has set out the outcomes which it would like to see developed and used within cancer care in England (Department of Health, 2011) The Department of Health cited research by Maddams within this document which predicted that by 2030 there will be more than three million people who will have been treated for cancer and survived, of which a third will be of a working age. The report emphasised the holistic nature of the patient experience acknowledging the financial and emotional aspect as well as the more frequently cited physical aspects. It is a real intention of the government's health care system that patients should achieve as much independence as possible from both the health care system as well as their own support network. Specific aims are set out within the report, one of which is that there should be a decrease in the proportion of people who report unmet physical and psychological needs post-cancer treatment. This is a significant challenge when considered in the context of a 2010 report that detailed patient experience and reported fewer cancer patients than in previous reports had understood the information they were given even at the point of diagnosis (Department of Health, 2010). Specifically within Britain therefore, despite more adherences to time-targets, a cultural shift needs to be achieved from a process-driven system towards a more personalised one. Part of this process has seen the development of Holistic Needs Assessment (HNA) for people with cancer (National Cancer Action Team, 2011). The publication suggested that if the holistic needs of patients were identified patients would be more likely to be engaged with their care, and identify the possible resources or services available during later stages of their treatment. Another government publication published in the same year, Improving Outcomes-A strategy for Cancer Care (Department 
of Health, 2011) has also recommended outcomes derived directly from patients should form the basis of outcome measures. It would seem therefore that there are two influences that might recommend more qualitative methodologies for the ongoing care of H\&NC patients (i) the lack of clear and consistent QoL results (ii) a political expectation, which encourages the description of care at an individual level. It is within this context that the current study was devised. The purpose of which was to establish whether H\&NC QoL measures adequately reflect a) the literature on patient experience b) the reported experience of H\&NC patients undergoing curative treatment.

\section{Methods}

\subsection{Research design}

A qualitative methodology was used in order to identify the themes associated with the experience of H\&NC. Three different sources of information were systematically explored using a previously described method of analysing information (Attride-Stirling, 2001). The sources were:

1. The three most commonly used HRQoL questionnaires in the H\&NC literature; These had been identified by previous research carried out by Rogers et al (Rogers et al., 2007) who had reviewed a five year period (2000-2005) and reported on the range and most frequently used questionnaires.

2. A review of the literature that describes the H\&NC patient's experience of the condition, its treatment and sequelae;

3. Semi-structured interviews recorded and transcribed from six H\&NC patients. The interview questions were informed by the themes developed from the literature, in source 2 .

For each of the three sources the themes were derived using a thematic analysis protocol as described by Attride-Stirling (2001). The application of thematic networks is a way of organising qualitative data in a systematic way. The thematic-analysis entailed development of a coding-framework that could be used to analyse and categorise each of the three sources of data: The themes were generated independently for the HRQoL questionnaires; but the literature review was used as a way of forming the semi-structured interview structure. This meant the process was sequential and relied upon the literature generating the initial interview structure. In effect the third source was dependent on the themes described in the second. Following categorisation, basic themes that evolved from each source were grouped, re-read and re-framed. The intention was to identify underlying patterns that might not be apparent on reading each in isolation. Finally, a review process took place in order to decide which organising themes were discrete or broad enough, to represent a group of ideas. The themes that were identified were organised in relation to one another such that they could be classified as either super-ordinate, or sub-ordinate to one another. Using the Attride-Stirling (2001) thematic analysis this meant that the themes were classified as basic, organising or global thematic networks. Independent assessment was provided to confirm the validity of the themes. Diagrams which represent and summarise visually the global themes between each of the three sources are presented within the section marked findings. 


\subsection{Data gathering}

\section{Source 1: Thematic analysis of HRQoL questionnaires}

Rogers et al (2007) had previously carried out a structured review of the H\&NC QoL literature in order to determine what questionnaires were used within the research. Three HRQoL questionnaires had been identified as the most commonly used within the research over a five year period (2000-2005). These were: The University of Washington (Hassan and Weymuller, 1993); the EORTC C30 and H\&N C35 (Bjordal et al., 1994, Bjordal and Kaasa, 1992); which are used in conjunction to one another and the Functional Assessment of Cancer Treatment -Head and Neck Subscale FACT (List et al., 1990). Thematic analysis was carried out on these questionnaires.

The areas represented by each questionnaire require patients to describe in the past week which statement is most representative of their current situation. The University of Washington (UoW) reviews: pain, appearance, activity, recreation, swallowing, chewing, speech, shoulder function, taste, saliva, mood and anxiety. Patients also represent these aspects of their health or function by one of five statements, which grade their abilities from 'no' to 'severe change' in function. Patients also have to identify three domains that are most affected, rate their health to prior to the cancer diagnosis, during the past week and their overall quality of life during the past week from outstanding through to very poor. The Functional Assessment of Cancer Treatment -Head and Neck Subscale (FACT H\&N) has a five point scale ranging from a description of "not at all" to "very much" examining specific areas and which include: seven questions re physical well being, seven questions regarding social well being six questions regarding emotional well being and seven questions regarding functional well being one of these questions asks the patient to rate their current satisfaction with their QoL. There are also twelve H\&NC specific questions that investigate eating, communication, appearance, smoking, and drinking behaviours and pain. The EORTC reviews via a four-point likert scale with descriptors ranging from "very much" to "not at all" the presence of the quality a range of issues. The general questionnaire EORTC C30 is composed of 30 multi-item scales and single items assessing areas of functioning (physical, role, emotional, cognitive, and social), as well as general symptoms -fatigue, pain, emesis, dyspnea, insomnia, appetite loss, constipation, and diarrhea. The patients are also asked to rate on a seven-point scale their attitude to their own health and quality of life status over the past week. The disease specific module EORTC H\&N35 consists of 35 questions including seven symptom scales: pain, swallowing, senses, speech, social eating, social contact, and sexuality. There are 11 additional, single items covering problems with teeth, mouth-opening, dry mouth, sticky saliva, cough, feeling ill, weight loss, weight gain, use of nutritional supplements, feeding tubes, and painkillers. The patient can complete all three questionnaires independently.

\section{Source 2: Thematic review of the literature}

A literature search was carried out in July 2009 using MEDLINE, EMBASE, the Science Citation Index (ISI), the Cumulative Index to Nursing and Allied Health Literature (CINAHL), the PsycINFO, the Allied and Complementary Medicine (AMED) and Global Health databases to review the literature surrounding H\&NC patients' experience and or coping with the disease The search terms used were "head and neck cancer" and 
"experience"; and "head and neck cancer" and "coping". There was also a manual review of topic areas specific to experience and H\&NC.

\section{Source 3: Thematic analysis of patients' perspectives.}

A purposive sample of six H\&NC patients was recruited for the study from a UK cancer centre. The bio-clinical details and treatment undergone for each participant are presented in Table $1 \mathrm{a}$ and Table $1 \mathrm{~b}$.

\begin{tabular}{|c|c|c|c|c|c|c|c|}
\hline & Sex & Age & Smoker & ${ }^{*}$ Alcohol & Job & Tumour site & ${ }^{* *}$ Pathology \\
\hline $\mathbf{n}$ & \multicolumn{7}{|c|}{} \\
\hline $\mathbf{1}$ & $\mathrm{f}$ & 68 & $\mathrm{X}$ & none & Secretary & $\begin{array}{c}\text { Mandibular } \\
\text { alveolus }\end{array}$ & PT4N0 \\
\hline $\mathbf{2}$ & $\mathrm{m}$ & 45 & $\sqrt{ }$ & $\leq 21$ & Craftsman & $\begin{array}{c}\text { Floor of } \\
\text { mouth }\end{array}$ & PT2NO \\
\hline $\mathbf{3}$ & $\mathrm{m}$ & 68 & $\mathrm{ex}$ & $\leq 7$ & Health wk & Laryngeal & PT1N0 \\
\hline $\mathbf{4}$ & $\mathrm{m}$ & 62 & $\sqrt{ }$ & $\leq 21$ & Hairdresser & Laryngeal & PT4N1 \\
\hline $\mathbf{5}$ & $\mathrm{m}$ & 66 & $\sqrt{ }$ & $\leq 21$ & Accountant & Laryngeal & PT4N2b \\
\hline $\mathbf{6}$ & $\mathrm{f}$ & 82 & $\mathrm{ex}$ & $\leq 7$ & Linguist & Buccal & PT4N1 \\
\hline
\end{tabular}

*number of units of alcohol consumed in a week

** pathological classification UICC $6^{\text {th }}$ edition

Table 1a. Bio-Social Statistics of participants $n=6$

\begin{tabular}{|c|c|c|c|c|c|}
\hline & Surgery & $\begin{array}{c}\text { Neck } \\
\text { dissection }\end{array}$ & RT & $\begin{array}{c}\text { Chemo } \\
\text { RT }\end{array}$ & Complications \\
\hline \multicolumn{6}{|c|}{$\mathbf{n}$} \\
\hline 1 & $\begin{array}{c}\text { Scapula-flap (failed) } \\
\text { Pec major }\end{array}$ & Unilateral & $\sqrt{ }$ & & $\begin{array}{c}\text { flap failure } \\
\text { salvage surgery pec } \\
\text { major }\end{array}$ \\
\hline 2 & $\begin{array}{l}\text { Radial fore arm free } \\
\text { flap }\end{array}$ & Bilateral & $\mathrm{X}$ & $\mathrm{X}$ & $\begin{array}{l}\text { Paralysed tongue } \\
\text { due to neuro praxis } \\
\text { of tongue }\end{array}$ \\
\hline 3 & Laser excision & None & $\mathrm{X}$ & $\mathrm{X}$ & None \\
\hline 4 & $\begin{array}{c}\text { Pharyngo- } \\
\text { Laryngectomy } \\
\text { Free flap (ALT) } \\
\text { Tracheal oesophageal } \\
\text { puncture } \\
\end{array}$ & Bilateral & $\mathrm{X}$ & $\sqrt{ }$ & $\begin{array}{l}\text { Infected donor site } \\
\text { skin grafts }\end{array}$ \\
\hline 5 & $\begin{array}{c}\text { Pharyngo- } \\
\text { Laryngectomy } \\
\text { Tracheal oesophageal } \\
\text { puncture }\end{array}$ & Bilateral & $\mathrm{X}$ & $\sqrt{ }$ & $\begin{array}{l}\text { Trachy pre surg at } \\
\text { time of biopsy }\end{array}$ \\
\hline 6 & Fibula flap & Unilateral & $\sqrt{ }$ & $\mathrm{X}$ & None \\
\hline
\end{tabular}

Table 1b. Treatment and complications for participants 
The participants were eligible if it was a year since the definitive treatment date of a squamous cell carcinoma, were judged to be cognitively intact and able to speak English. Thirty questions acted as the structure of the interview and are reproduced in Table 2. A year post-treatment was judged an appropriate time-interval so that participants would

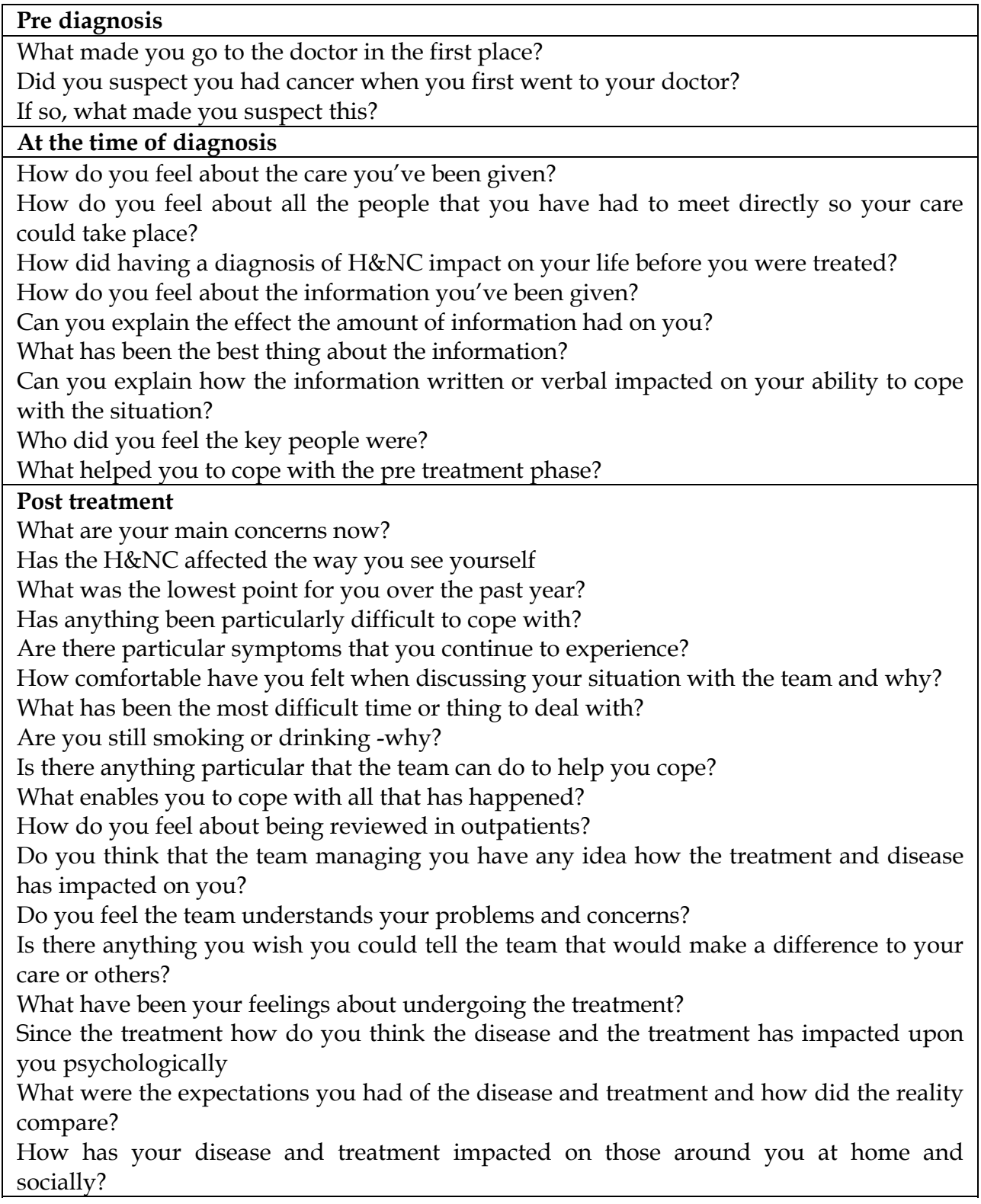

Table 2. Questions used to generate interviews of the H\&NC patients. 
have recovered from the acute phase of treatment and not be overwhelmed by some of the pervasive physical symptoms that have been well documented (Rogers, 2010). Each interview was digitally recorded and independently transcribed before being analysed by the primary researcher. The length of interview ranged from 40-70 minutes.

\section{Findings}

\subsection{Findings from questionnaires, literature and semi-structured interviews}

Six global themes were evident; four from all three sources: day to day physical comfort, emotional well being, place in society and own mortality; one from the literature and semistructured interviews; quality of care; and one from the semi-structured interviews: reality.

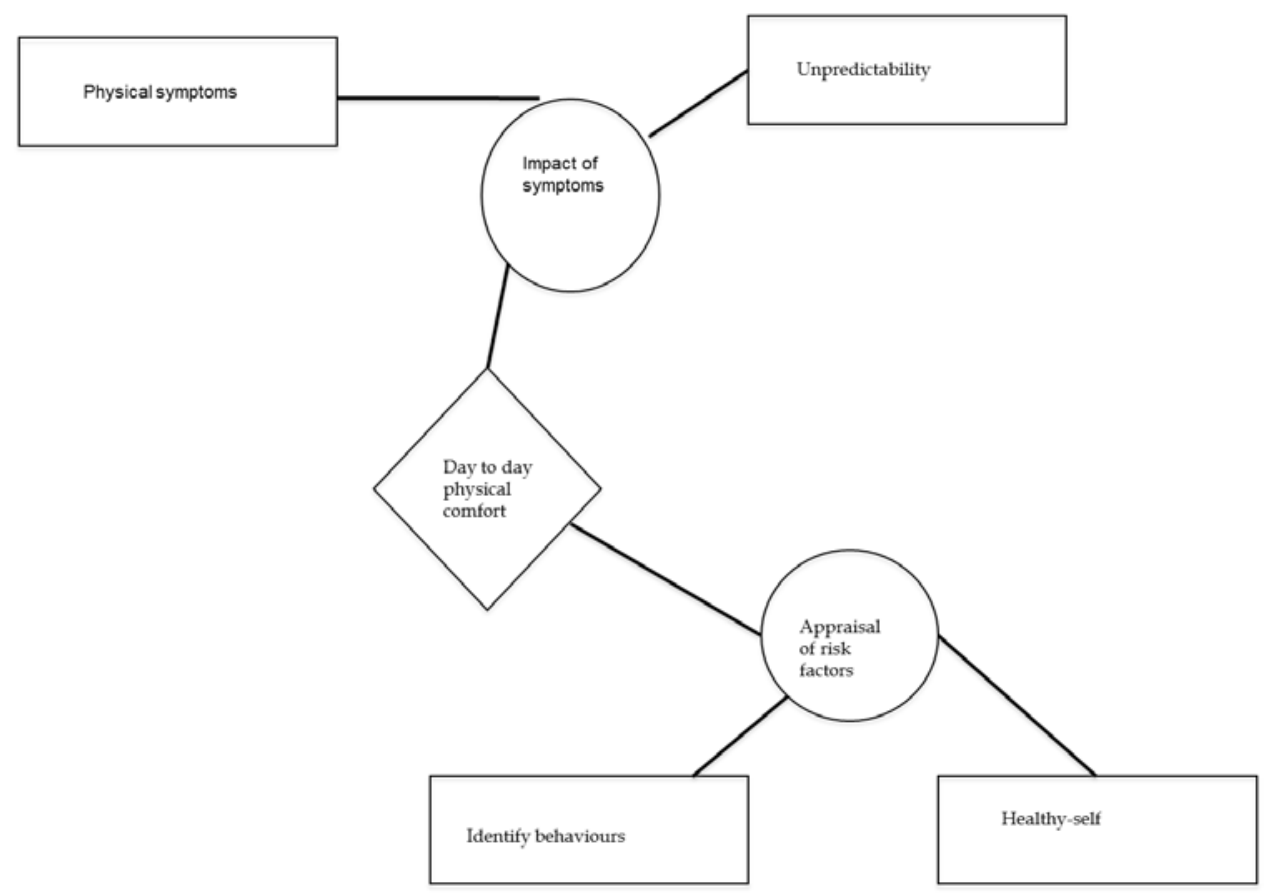

Diagram 1. Thematic network: Day to day physical comfort

The global themes that were evident from all three sources however differ in the detail covered. The questionnaires were at a basic theme level and remained at the identification and quantification of symptoms function and role. The literature and semi-structured interviews revealed a wider range of physical and emotional symptoms and demonstrated increased subtleties. This meant that there was more explanation into how participants coped with physical and emotional symptoms, as well as place in society.

Participant 1: “We have an away day in October. I said I don't think I can go because I think it would bother me. They said "oh no we would ask for something special for you at mealtimes" I said "no I don't want to eat around a table with people, if I could just bring my 
drinks and be somewhere separate where no one would bother me or say "come and eat with us" then I'll come."

Participant 2: "People don't know how much you rely on your tongue. There are a lot of things I can't do. I can't touch the top of my lip. If I get a piece of meat stuck in the back of my tooth, before I'd use my tongue..... But now I can't. I have to use the toothbrush to get it out.... There's no point in getting irritated because I can't change it. I might do it one day but I just get on with it."

Participant 3: You try not to let it get to you, how bad you are and the pain you're in(pointing at anterior lateral thigh donor site) so you cope with it more because if you're not showing it you can cope."

All three of the above semi-structured interview excerpts describe symptoms and function eating in public, reduced tongue mobility and the ongoing issue of pain- but also describe what strategies the participants use to over come them.

Whilst as a basic theme identification of primary risk behaviours such as tobacco and alcohol use were evident within one of the three questionnaires-the FACT (I smoke Cigarettes; I drink alcohol); the semi-structured interviews were able to develop the theme into a personal appraisal of such behaviours being renewed.

Participant 2:“I was diagnosed on the Wednesday, I went outside and lit up; I had half a cigarette and went home, had a cup of tea and a sandwich and smoked half a cigarette. About five o'clock, I lit up another cigarette up and had half. I finished the other half about eight o'clock and I said when I go to bed tonight I'll have a cigarette in the morning. I woke up and never touched one.

I used to smoke thirty or forty per day. I don't know how I just stopped and I'd been trying to pack up for ten years as my New Year resolution"

Participant: 3 More than ever, I still crave a cigarette I've actually banned it from the house now. If it's raining I'll let them smoke in the kitchen with the door closed and the windows open but it's not for me."

Within the global theme place in society the HRQoL questionnaires revealed the basic theme of personal roles identified at work, - "my work is fulfilling" and within social and family circles "I get emotional support from my family", " I feel close to my partner" (FACT $\mathrm{H} \& N)$. Within the interviews the global theme was expressed more in terms of the alienation from society and the purpose of some roles that participants had. Participants were very specific and actively chose who would or would not know about the diagnosis and the treatment, a way of maintaining a particular role but which within the FACT might still be labelled as having family support and so overlook certain choices made to protect other members of the family.

Participant 1:“I couldn't tell my brother and sister, or my children. One of my sons had a first child on the way and he was born three days after I left the hospital so I couldn't possibly worry him. ........My younger son had had a terrible accident when he was ten months old, he poured a kettle over himself, so knowing that I had mouth cancer, I didn't 
even want him to come and see me, I thought it would bring it all back to him, so I shut them out of life whilst I was in the hospital."

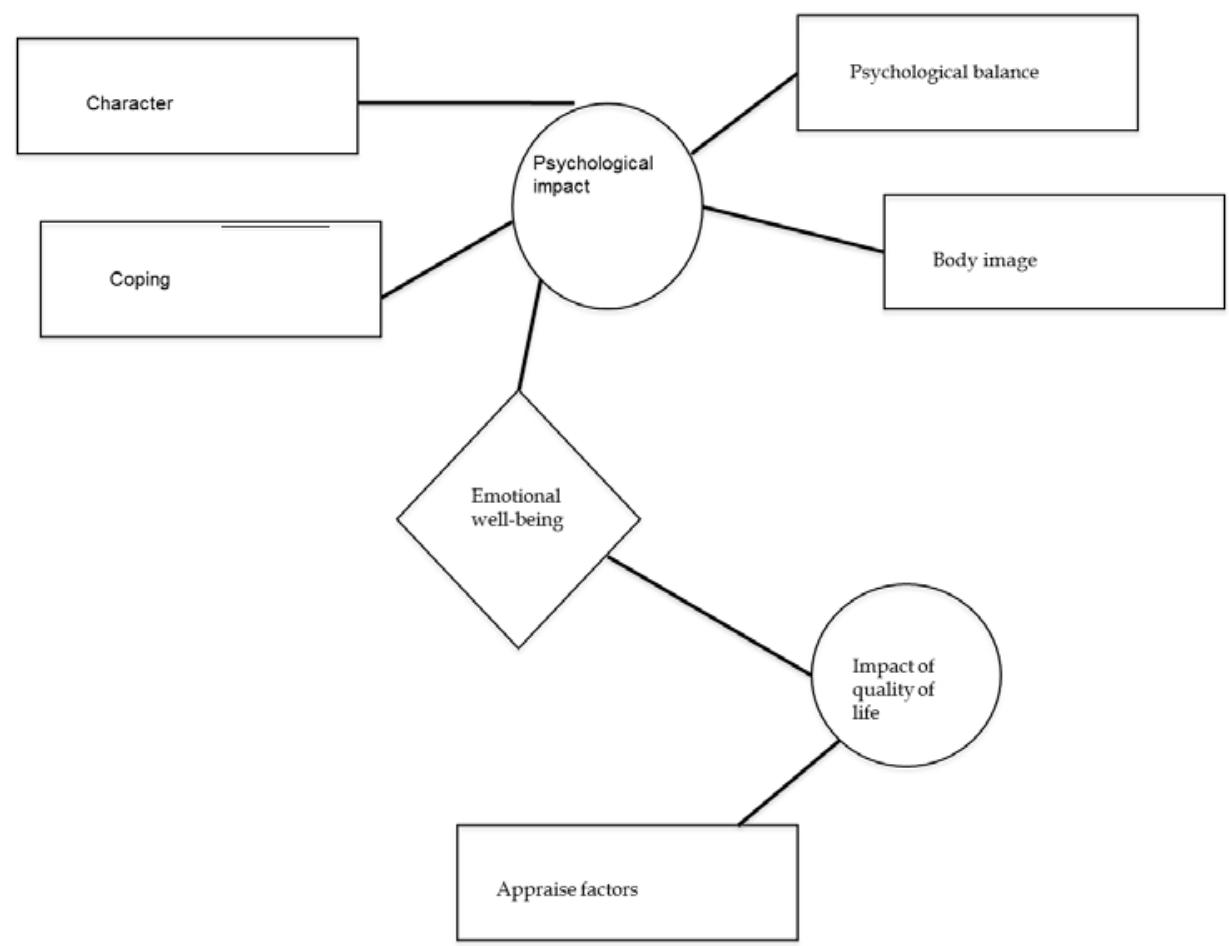

Diagram 2. Thematic network: Emotional well-being

The semi-structured interviews also revealed the detail of explicit secondary gain that predominantly focussed around enhanced relationships. This included the adjustment of values and priorities such that more time was spent with family members. Situations were also reappraised in the context of health and survival.

Participant 4: "I allow a lot of trivialities to go out the window, which I wouldn't have done before.........domestic situations at home, I'll break something it would have bothered me before, and I would have fixed it quickly but it can wait. I'll get it done when I feel like it when it's convenient......... I can't wait to see my grandkids. It makes you more appreciative of your family."

The final common theme between all three sources "Own Mortality" was again explored to different depths by each source. Within the HRQoL questionnaires it was evident with the FACT questionnaire "I worry about dying" In the literature it was explored through the theme of disease recurrence- a substantial part of the H\&NC survivor literature (Llewellyn et al., 2008, Humphris et al., 2003)and an acceptance that death is a possibility (Chaturvedi et al., 1996). Fear of recurrence within the semi-structured interviews was openly expressed.

Participant 5 "Now and then I worry it might come back." 
Participant 1 "Now and then the worry comes over you. I don't worry if it will come back; I wonder if I would have the courage to meet new people with that diagnosis again, I'm ok where I am."

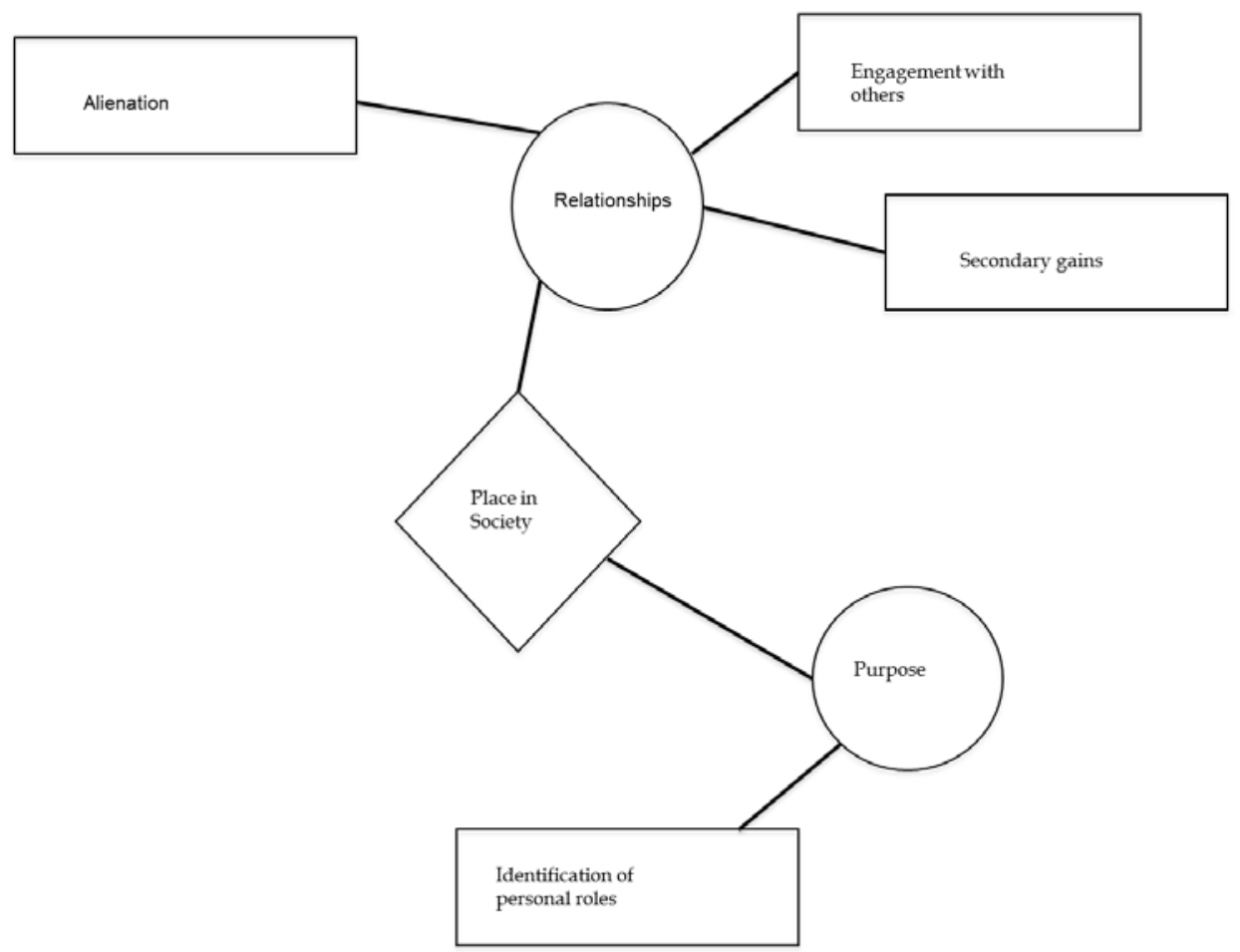

Diagram 3. Thematic network: Place in society

There was acknowledgement that participants had actively prepared for the possibility of dying soon after treatment. Five of the six participants had made personal preparations in the event of not recovering enough to adequately deal with personal effects.

Participant 1: “All day for a couple of weeks I didn't think I would survive the operation and I knew the house would have to be cleared so I just spent day after day clearing books. One day I had eight bags for the charity shop."

Two participants within the global theme of mortality expressed regret at having the treatment. There was a sense of reappraisal in the context of having the treatment and an admission that the current existence was hard to reconcile because of the change in function.

Participant 3: "I wish to God now that I had not had it done and I would have just carried on for twelve months with a bottle in one hand, well not for twelve months I most probably would have had three. I'm not used to being ill for longer than a couple of weeks."

One of the participants commented on the difference for them between the questionnaires and an interview discussion. 
Participant 4: "if you do the normal surveys when you've come round and asked me questions, I tick and cross the response but I don't think I give out that much information,........... but some people like me when you start talking never stop and then you find out so much in twenty minutes, -all in one go."

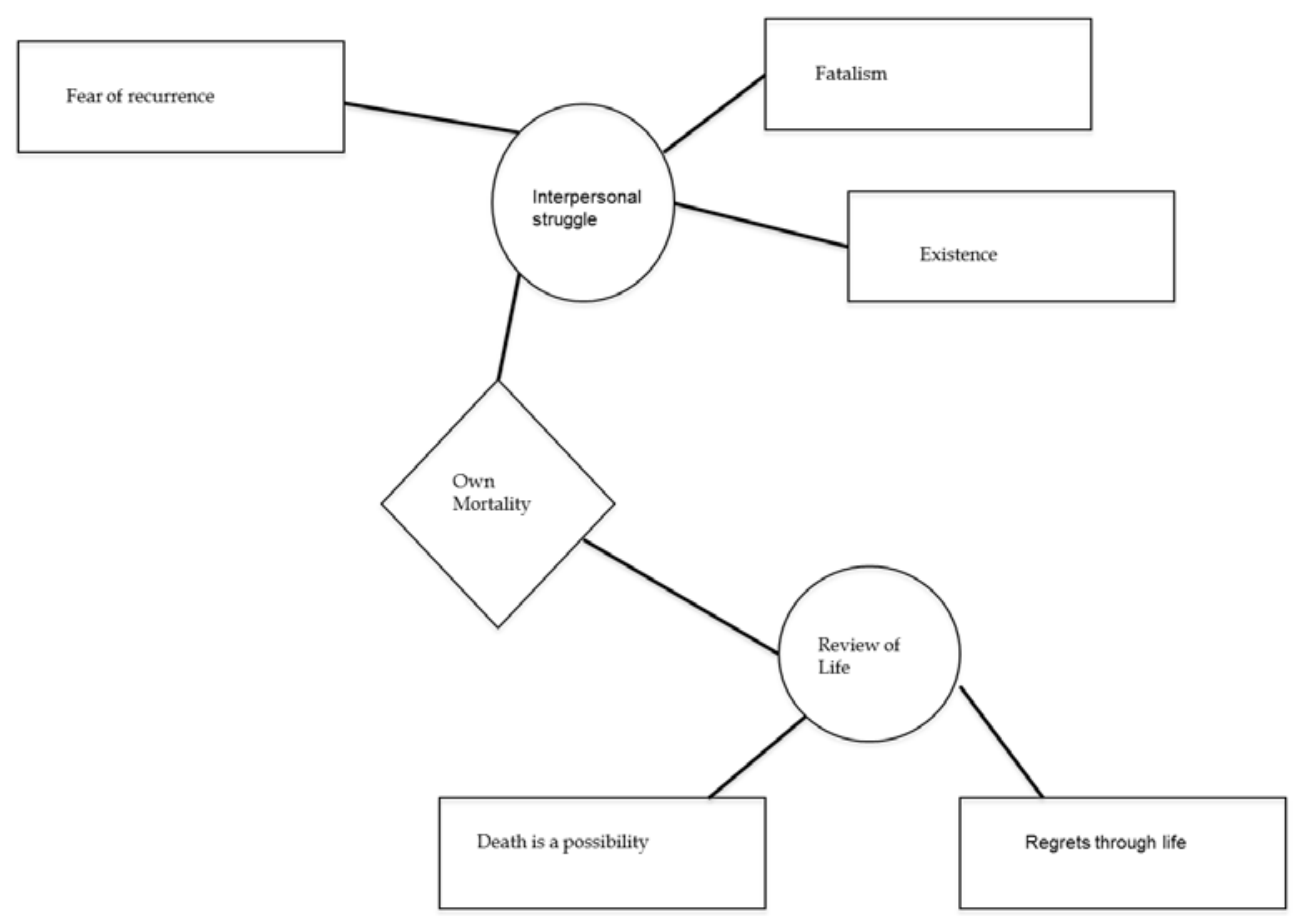

Diagram 4. Thematic network : Own mortality

\subsection{Findings from literature and interviews}

The literature and interviews added a further global theme: quality of care.

The quality of care theme was able to illustrate patient vulnerabilities and assumptions that might be present during the treatment process. There was a sense from participants interviewed that it was not possible to really appreciate how long it would take to begin to recover from the treatment. The semi-structured interviews gave evidence of the difficulty participants had in the assimilation of written and verbal information, and more specifically the implications of not understanding information. One participant explicitly described how it was difficult to appreciate what the real meaning was of a neck dissection until it had happened, relating it then to physical changes.

Participant 2: "The surgeon was saying what he was going to do, he said he would cut me from here to here and he would take my glands out. I understood but I suppose I didn't understand the extent of what the operation involved. Does that make sense? They are alien words; when you say you are going to make a line from here to here and take away glands I 
don't really know what that means. I didn't know the glands were as big as they were. It was obvious what was happening but I didn't understand what it would mean."

Another described how despite needing three operations within the space of three weeks it was not possible to be prepared any more comprehensively because of it being so difficult to predict the course of recovery. Research has concluded that the timeliness, individuality and amount of written and verbal information given to patients are vital if trying to reduce evident mismatch between patient expectations and experiences (Llewellyn et al., 2008, Llewellyn et al., 2006).

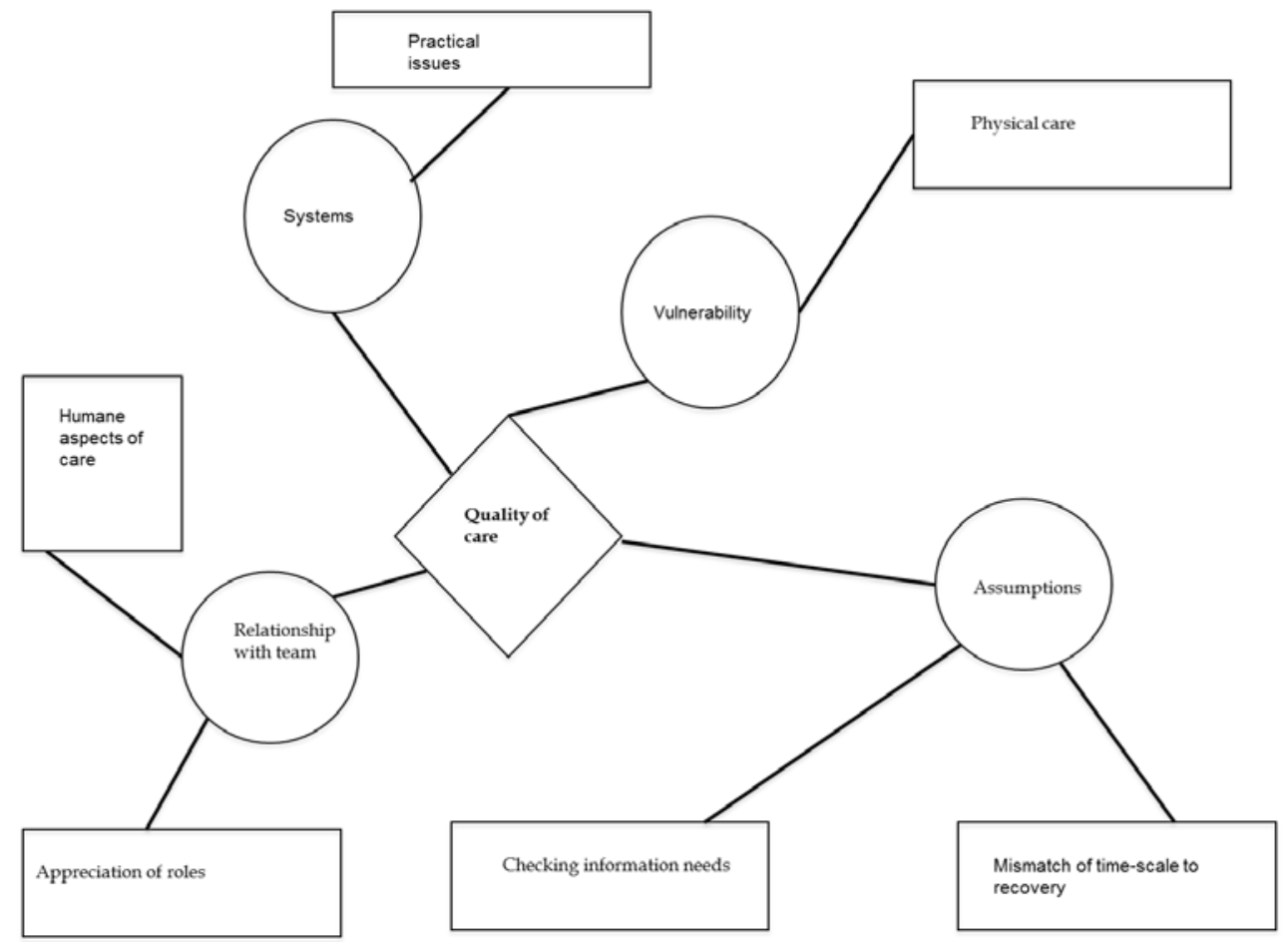

Diagram 5. Thematic network: Quality of care

A substantial organising theme was the relationship with the team. Examples were given within the literature of individual and patient orientated care and although the teams judged this as time consuming,(McLane et al., 2003) it was seen to have value and focus to the team and patient interactions. H\&NC patients undergoing treatment have been described as resilient and resistant to offers of help (Wells, 1998), an issue echoed within the semi-structured interviews when a participant described not wanting to bother busy ward staff unless there was a real need. For example it might also be that there is some difficulty in patient compliance and adherence to treatment programmes that needs to be identified and addressed (Edmonds and MaGuire, 2007). Specific to the semi-structured interviews there was evidence of institution organisation difficulties. These included logistical and 
practical issues relating to appointments. Both the literature and semi-structured interviews disclosed information relating to the humane judgments in patient care. There was evidence to suggest that it was expected that there would be good advanced communication skills used, which would result in a consistent and understood message from the teams (Moore et al., 2004, Llewellyn et al., 2006). Specifically the semi-structured interviews highlighted the utter trust, vulnerability and belief in key members of the clinical team that the participants had.

Participant 1 "Well you couldn't be in better hands anywhere in the world, from first meeting my surgeon I had no fear and trusted him. I always felt better when I left the appointment he was just so down to earth and gave me so much confidence."

Participant 2 "And the surgeon's reputation is important, because you're thinking if you are going to do this to me, and you are telling me its going to work, I have to believe you are the best to do it, because if I don't then you are completely lost...They don't make you feel like a number. If I've got a problem I can raise it with somebody. It's not as though you go to the bottom of the pile and have to repeat it all the next time you visit they remember the conversation and what was on your mind at the last appointment."

\subsection{Findings from the semi-structured interviews}

The semi-structured interviews revealed a specific global theme, reality that reflects some of the stoical aspects of the participants in dealing with the situation. In this context participants described unremitting symptoms, the acceptance of being reactive rather than in control, the need for an inner strength and the stark choices that had been faced during the assessment and treatment phase of their disease. Participants did not perceive choice at the time of treatment because in reality little choice existed in deciding whether to have treatment.

Participant 5: You've got no option, it's that or nothing, so you have to have it done you don't have to think about it at all-there is no choice."

The perceived choice by others was not in reality available to the participants. This aspect of stark choices linked to the basic theme of alienation that participants felt in the global theme "place in society". The inner strength that became an organising theme was made up of examples of physical and emotional loneliness and a sense of if the participants did not deal with the issues then no one else would.

Participant 3 “I just worried that I'm not going to feel much better and I'm finding it difficult to cope."

Participant 5 "The days pass and you go to sleep and you relax and you don't think about it even with the tube in your neck (tracheostomy) you have to learn to switch off and let the nurses do the worrying."

There was also evidence of unremitting symptoms, both physical and emotional that were continually present and difficult to ignore. This in part explained the reactive state that participants expressed in which they were not able to take control of certain symptoms. There was a sense of needing to wait to heal; knowing that to be too active would lead to frustration, fatigue and deterioration in function. 
Participant 6: "For me it is a very ongoing thing and also to the point where you can have what are called one of my 'good days' and you think this is great only to feel the next two days are horrid and you think I'm back to where I was. I count my good days and enjoy and do what I can .... You have to let time pass, you can't hurry (the recovery) and you have to let it go at it's own pace."

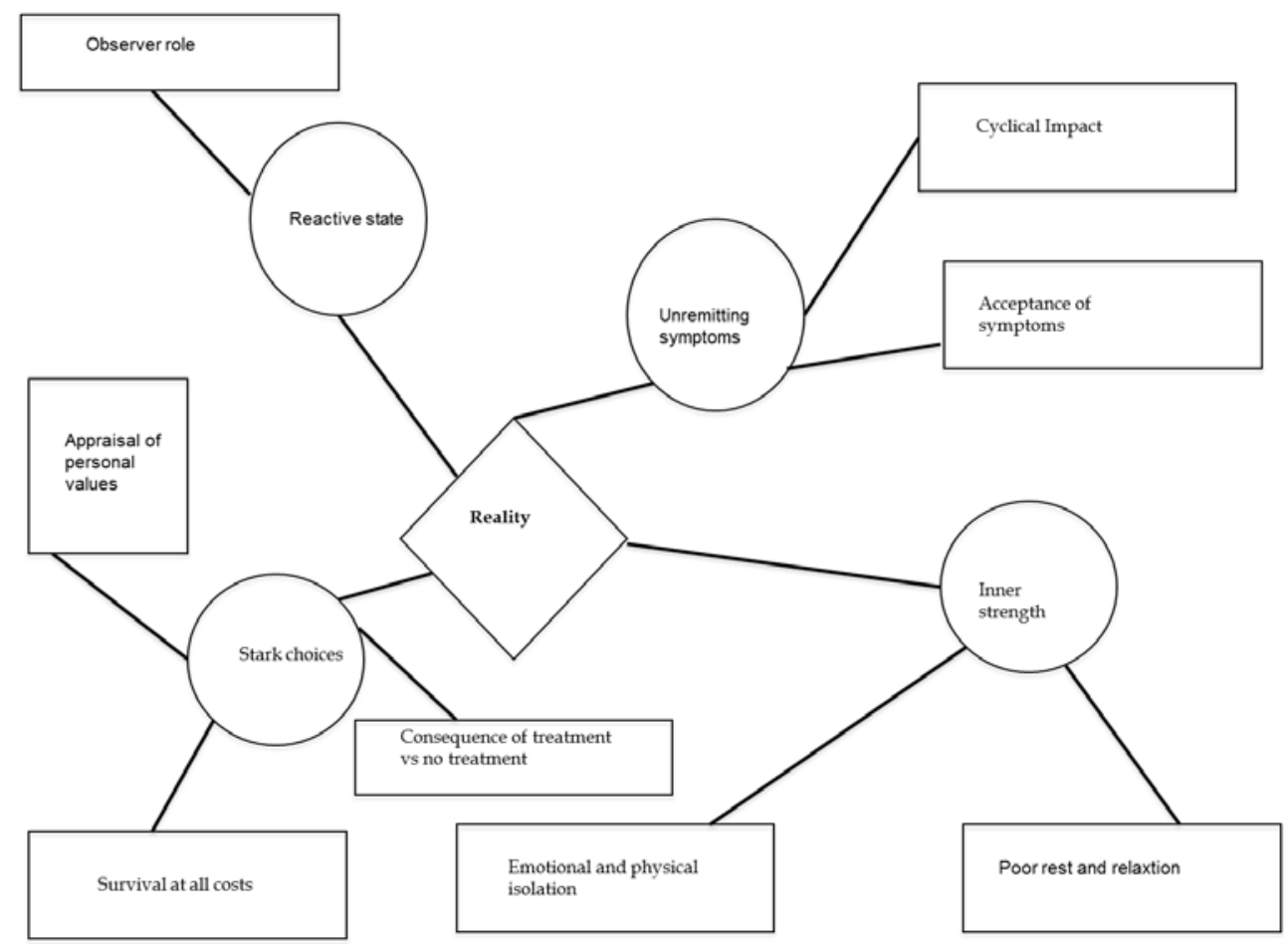

Diagram 6. Thematic analysis: Reality

The evident stoicism and depiction that participants presented that they were emotionally coping hid the reality of the gruelling impact that participants dealt with.

Participant 3 “Once you let your defences down that's when you start to crumble, so it's as though I'm standing on the outside of the building, but I've crumbled inside, there are times in the last few weeks I've felt 'oh hell what's the point, I'm not bothered but I don't let on."

From the semi-structured interviews it was possible to represent the global themes from statements made by the patients such that statements could be categorised under the global themes and perhaps give some real salience to the experience of the disease and treatment of H\&NC. Diagram seven represents the 45 statements under one of the six global themes. 


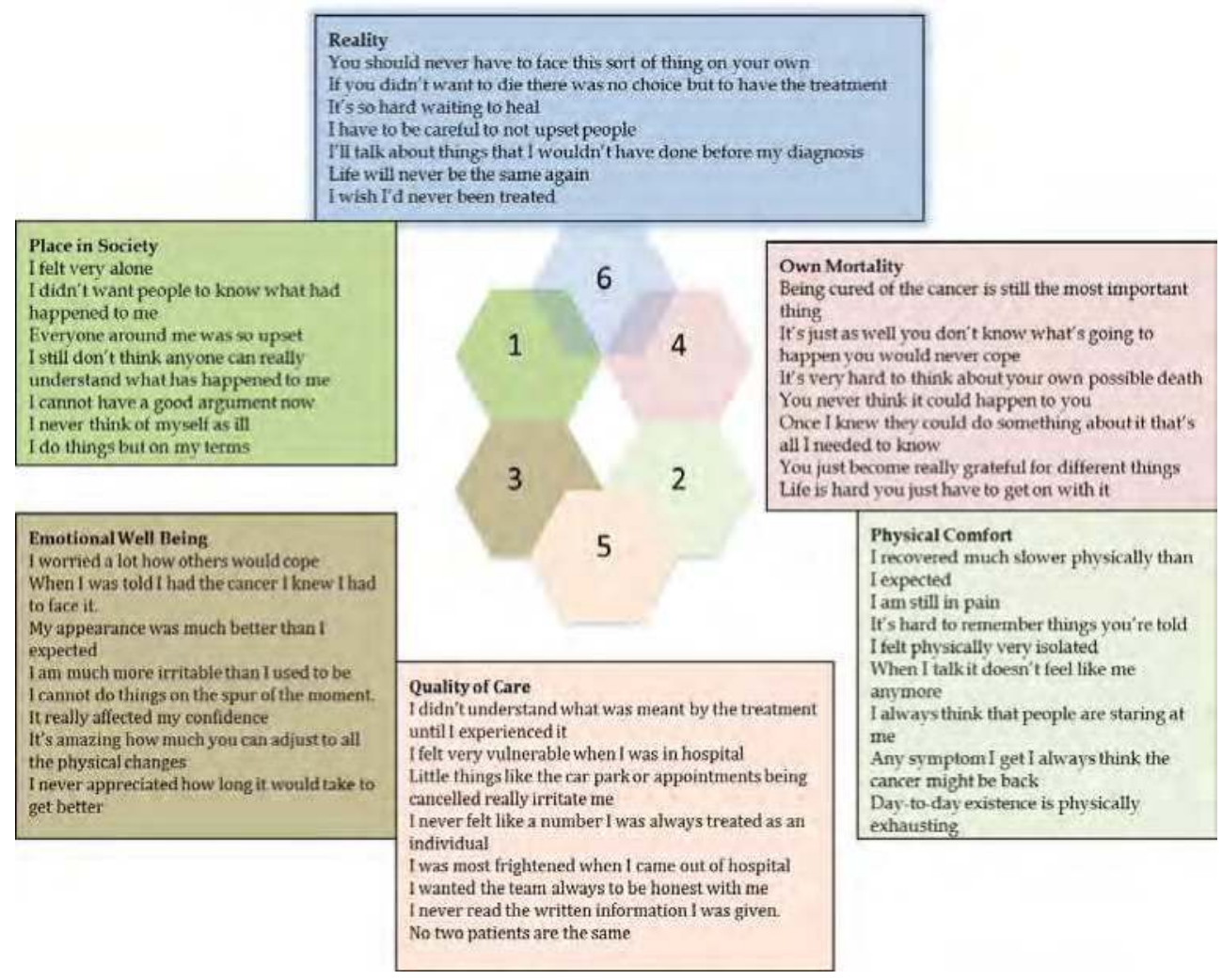

Diagram 7. Statements from participants that represent six themes.

\section{Discussion}

Three sources of information relating to the experience of H\&NC have been thematically analysed using a previously described approach (Attride-Stirling 2001). HRQoL questionnaires focus on symptoms and function, which mean they remain at the level of basic themes. They do not allow the influences or the connections between scores to be understood so that patient adjustment and reappraisal when undergoing treatment is poorly represented. Whilst there might be changes identified by HRQoL questionnaires when they are repeated, there is limited explanation as to how the patient might have achieved this or the relevance of the symptom or change in function for the patient. This perspective is verified further in the context of the literature which has suggested that H\&NC patients will under-report symptoms, due in part to a sense of hopelessness and loss of meaning to life following treatment for the disease (Moore et al., 2004). It might be therefore that the use of HRQoL questionnaires under-represents patients' real experience both in terms of intensity and scope.

This investigation of the experience of H\&NC enables one to conclude that there are perhaps complex and interactive patient characteristics that will impact on the H\&NC patients' QoL 
scores. The semi-structured interviews identify in participants a reappraisal of values, numerous coping strategies, and adaptation. It might therefore be that HRQoL questionnaires are measuring other effects, that modify patients' scores which are not directly related to the treatment and disease and which might, if better understood, give insight to the patient, carers and health care team which might secure a more successful management of the patient. A specific example of this can be seen within health behaviours. If a patient is still smoking or drinking alcohol the behaviour should not only be identified but have a patient specific commentary so that the health care professional might become more informed of the context for the continuing behaviour. If this could happen cessation programmes if appropriate might be more successful. Assessment of the existence of risky behaviours is only evident within one of the three most regularly used HRQoL questionnaires the FACT. It would seem therefore discussion of health behaviours is poorly represented within HRQoL questionnaires.

The current study demonstrates that the focus of HRQoL questionnaires is narrow and that it is important to build a context in which the HRQoL variables are a part rather than the whole. Whilst physical, emotional symptoms and personal relationships are a substantial part of a patient's description of their well-being they are not the complete picture. In order to achieve this, patients' needs and possible current limitations, quality of care and the reality of the situation for them as individuals should be discussed. If this aspect of the whole person can be better understood then personalised care can be described and care plans created which meets UK government policy (National Cancer Action Team, 2011). It might also be that the process of semi-structured discussion allows a patient to review their concerns and have them recognised as important aspects of their care. Through this method of investigation the health care team might begin to truly understand, in the context of the patient's own previous life-experiences why they might have reacted in a particular way during their treatment and recovery. Such understanding and reflection might allow patients to recognise at an earlier stage their needs, which might avert a crisis; a further intention of the Holistic Needs Assessment set out by the National Cancer Action Team (2011). It might also mean that patients are able to discuss and understand dissatisfactions in life without having feelings labelled as either anxiety or depression.

It has been suggested by Salander (Salander, 2011) that the added burden of the cancer diagnosis and treatment prompts patients to seek support in order to lessen the total psychological burden. He went onto suggest that whilst patients need medical input to cure them of the cancer they are capable of lessoning some of the emotions associated with the situation. As part of this process they may respond well to the opportunity to reappraise their life. Within a treatment paradigm patient data should not only act as a descriptor but also as a way of formulating a treatment plan. If this could be achieved, studies would move beyond recognising the presence of the impact towards aiming to describe more specifically how treatment has affected patients. Discussion via semi-structured interview enables much more explanation of the patient's situation and allows for the true context of the symptom or feeling to be described. This approach is more holistic and might allow for the medical team to make judgements with the patients, which relate to their tolerance of the situation. This method of enquiry is less likely to be open to misinterpretation and might add more satisfactorily detail so that care-plans might be formulated. It might be that HRQoL 
questionnaires can act as a screen of needs assessment for some of the more obvious physical and emotional impacts of the disease and treatment, but they should not take the place of detailed discussion between the team and patient, and in no way can they be said to be representative of the whole experience.

\section{Conclusion}

Outcome should be represented in more meaningful terms than length of survival or clinical process targets. HRQoL measures might identify some of the more superficial aspects of outcome but a more rounded understanding of the covert aspects may positively support both the patient and their carers through such life-changing experiences. HRQoL questionnaires cannot be said to adequately reflect either the available literature on patient experience or the reported experiences of H\&NC patients themselves. Review of all three sources would suggest that when used HRQoL questionnaires are used there is a narrow, symptoms biased collection of information. The questionnaires cannot capture the wealth of the data that is potentially available or offer an explanation to some of the measures that are taken.

Health care teams, patients and their families should understand the impact of H\&NC and its management from a holistic perspective so that the care can be achieved successfully for each individual. HRQoL measures by necessity have a narrow focus on symptom and function and these can be mistakenly seen as representing a patient's QoL rather than as some of the constituent parts. Within a clinical setting it would seem valuable to routinely invite patients who have undergone treatment to discuss, in a semi-structured way, the individual impact of the disease and the treatment. The purpose of this would be to facilitate a deeper understanding through explanation of the individual experience and to enable specialist teams to support patients more appropriately in outpatient settings. If this were to happen it would enable teams to move away from the quantifying process, in which a change in score has limited real meaning towards more a detailed explanation. Moving towards a more holistic needs assessment should enable patients to explain what has happened to them and to appreciate a more complete picture of the impact. If this could be achieved one might expect that a patient is less dependent on others for their well-being and that they could seek help earlier. There should be a recognition that patients' minds are intrinsically linked to their physical status and are not well represented because they are hard to describe in a meaningful way.

This study only examined the experience of six H\&NC patients' experience of their treatment within a UK cancer centre. The statements gathered from them can be used in a more formal way to investigate the experiences of other H\&NC patients. A future study will use the list of statements generated from the six identified themes with other H\&NC patients and invite them to rank them according to how like or unlike their experience of the disease the statements are. The current study has therefore acted as a way of creating a set of statements from three sources, and is part of the a method called Q Methodology, which has been described as a way of looking for patterns in the way people think (Webler, 2009). There is perhaps a role for more qualitative methodologies to be used alongside quantitative methods in order to discover what factors affect people who survive the disease, which to 
date has been poorly identified. This may allow a structured approach that is replicable with more groups of patients and this might be said to be an influential method of gathering key factors that are important for patients at an individual level. The ultimate goal will remain to collect information that can inform the management of patients who live with the consequences of a life changing event so that they can live as independently as possible from health care systems and carers.

\section{Ackowlegement}

The first author would like to thank Professor Carolyn Hicks, Mr Sat Parmar, and Mr Andrew Brown for their significant and most insightful professional support that they have provided over many years.

\section{References}

Attride-Stirling, J. 2001. Thematic-networks: an analytic tool for qualitative research. Qualitative Research, 1, 385-405.

Bjordal, K., Ahlner-Elmqvist, M., Tollesson, E., Jensen, A. B., Razavi, D., Maher, E. J. \& Kaasa, S. 1994. Development of a European Organization for Research and Treatment of Cancer (EORTC) questionnaire module to be used in quality of life assessments in head and neck cancer patients. EORTC Quality of Life Study Group. Acta Oncol, 33, 879-85.

Bjordal, K. \& Kaasa, S. 1992. Psychometric validation of the EORTC Core Quality of Life Questionnaire, 30-item version and a diagnosis-specific module for head and neck cancer patients. Acta Oncol, 31, 311-21.

Campbell, B. H., Spinelli, K., Marbella, A. M., Myers, K. B., Kuhn, J. C. \& Layde, P. M. 2004. Aspiration, weight loss, and quality of life in head and neck cancer survivors. Arch Otolaryngol Head Neck Surg, 130, 1100-3.

Chaturvedi, S. K., Shenoy, A., Prasad, K. M., Senthilnathan, S. M. \& Premlatha, B. S. 1996. Concerns, coping and quality of life in head and neck cancer patients. Support Care Cancer, 4, 186-90.

Curtis, J. R., Martin, D.P, Martin, T.R. . 1997;. Patient-assessed health outcomes in chronic lung disease: what are they, how do they help us, and where do we go from here? Am J Respir Crit Care Med 156, 1032-1039.

De Graeff, A., De Leeuw, J. R., Ros, W. J., Hordijk, G. J., Blijham, G. H. \& Winnubst, J. A. 2001. Sociodemographic factors and quality of life as prognostic indicators in head and neck cancer. Eur J Cancer, 37, 332-9.

Department Of Health 2010. National Cancer Patient Experience Survey Programme - 2010 National Survey Report.

Department Of Health. 2011. Improving Outcomes: A Stratedgy for Cancer [Online]. Available:

http://www.dh.gov.uk/prod_consum_dh/groups/dh_digitalassets/documents/ digitalasset/dh_123394.pdf.

Edmonds, M. \& Maguire, D. 2007. Treatment adherence in head and neck cancer patients undergoing radiation therapy: challenges for nursing. 
Journal of Radiology Nursing, 26, 87-92.

Fang, F. M., Liu, Y. T., Tang, Y., Wang, C. J. \& Ko, S. F. 2004. Quality of life as a survival predictor for patients with advanced head and neck carcinoma treated with radiotherapy. Cancer, 100, 425-32.

Hammerlid, E., Bjordal, K., Ahlner-Elmqvist, M., Boysen, M., Evensen, J. F., Biorklund, A., Jannert, M., Kaasa, S., Sullivan, M. \& Westin, T. 2001. A prospective study of quality of life in head and neck cancer patients. Part I: at diagnosis. Laryngoscope, 111, 669-80.

Hammerlid, E. \& Taft, C. 2001. Health-related quality of life in long-term head and neck cancer survivors: a comparison with general population norms. Br J Cancer, 84, 149-56.

Hassan, S. J. \& Weymuller, E. A., Jr. 1993. Assessment of quality of life in head and neck cancer patients. Head Neck, 15, 485-96.

Howren, M. B., Christensen, A. J., Karnell, L. H. \& Funk, G. F. 2010. Health-related quality of life in head and neck cancer survivors: impact of pretreatment depressive symptoms. Health Psychol, 29, 65-71.

Humphris, G. M., Rogers, S., Mcnally, D., Lee-Jones, C., Brown, J. \& Vaughan, D. 2003. Fear of recurrence and possible cases of anxiety and depression in orofacial cancer patients. Int J Oral Maxillofac Surg, 32, 486-91.

Kanatas, A. N., Mehanna, H. M., Lowe, D. \& Rogers, S. N. 2009. A second national survey of health-related quality of life questionnaires in head and neck oncology. Ann R Coll Surg Engl, 91, 420-5.

Karvonen-Gutierrez, C. A., Ronis, D. L., Fowler, K. E., Terrell, J. E., Gruber, S. B. \& Duffy, S. A. 2008. Quality of life scores predict survival among patients with head and neck cancer. J Clin Oncol, 26, 2754-60.

List, M. A., Ritter-Sterr, C. \& Lansky, S. B. 1990. A performance status scale for head and neck cancer patients. Cancer, 66, 564-9.

Llewellyn, C. D., Mcgurk, M. \& Weinman, J. 2005. Are psycho-social and behavioural factors related to health related-quality of life in patients with head and neck cancer? A systematic review. Oral Oncol, 41, 440-54.

Llewellyn, C. D., Mcgurk, M. \& Weinman, J. 2006. How satisfied are head and neck cancer (HNC) patients with the information they receive pre-treatment? Results from the satisfaction with cancer information profile (SCIP). Oral Oncol, 42, 726-34.

Llewellyn, C. D., Weinman, J., Mcgurk, M. \& Humphris, G. 2008. Can we predict which head and neck cancer survivors develop fears of recurrence? J Psychosom Res, 65, 525-32.

Logemann, J. A., Smith, C. H., Pauloski, B. R., Rademaker, A. W., Lazarus, C. L., Colangelo, L. A., Mittal, B., Maccracken, E., Gaziano, J., Stachowiak, L. \& Newman, L. A. 2001. Effects of xerostomia on perception and performance of swallow function. Head Neck, 23, 317-21.

Mclane, L., Jones, K., Lydiatt, W., Lydiatt, D. \& Richards, A. 2003. Taking away the fear: a grounded theory study of cooperative care in the treatment of head and neck cancer. Psychooncology, 12, 474-90. 
Mehanna, H. M., De Boer, M. F. \& Morton, R. P. 2008. The association of psycho-social factors and survival in head and neck cancer. Clin Otolaryngol, 33, 83-9.

Mehanna, H. M. \& Morton, R. P. 2006a. Patients' views on the utility of quality of life questionnaires in head and neck cancer: a randomised trial. Clin Otolaryngol, 31, 310-6.

Mehanna, H. M. \& Morton, R. P. 2006b. Why are head and neck cancer clinicians not measuring quality of life? J Laryngol Otol, 120, 861-4.

Montazeri, A. 2009. Quality of life data as prognostic indicators of survival in cancer patients: an overview of the literature from 1982 to 2008. Health Qual Life Outcomes, 7, 102.

Moore, R. J., Chamberlain, R. M. \& Khuri, F. R. 2004. Communicating suffering in primary stage head and neck cancer. Eur J Cancer Care (Engl), 13, 53-64.

National Cancer Action Team. 2011. Holistic needs assessment for people with cancer [Online]. Available: http://www.ncat.nhs.uk/our-work/living-with-beyondcancer/holistic-needs-assessment.

National Institue for Clinical Excellence 2004. Improving supportive and palliative care for adults with cancer:the manual The Stationary Office London.

Reid, K., Hicks, C., Herron-Marx, S. \& Parmar, S. 2009. Effect of oral tumour size on quality of life judgements by health care professionals working with head and neck cancer patients: a pilot study. J Laryngol Otol, 123, 1352-7.

Rogers, S. L., D. Yueh, Bevan, A. Weymuller, E, A., JR 2010. The Physical Function and Social-Emotional Function Subscales of the University of Washington Quality of Life Questionnaire. J Arch Otolaryngol Head Neck Surg, 136, 352-357.

Rogers, S. N., Ahad, S. A. \& Murphy, A. P. 2007. A structured review and theme analysis of papers published on 'quality of life' in head and neck cancer: 2000-2005. Oral Oncol, 43, 843-68.

Ronis, D. L., Duffy, S. A., Fowler, K. E., Khan, M. J. \& Terrell, J. E. 2008. Changes in quality of life over 1 year in patients with head and neck cancer. Arch Otolaryngol Head Neck Surg, 134, 241-8.

Salander, P. 2011. Why doesn't mind matter when we are to find out what is helpful? Psychooncology, 20, 441-2.

Scharloo, M., Baatenburg De Jong, R. J., Langeveld, T. P., Van Velzen-Verkaik, E., Doorn-Op Den Akker, M. M. \& Kaptein, A. A. 2005. Quality of life and illness perceptions in patients with recently diagnosed head and neck cancer. Head Neck, 27, 857-63.

Sollner, W., Devries, A., Steixner, E., Lukas, P., Sprinzl, G., Rumpold, G. \& MAISLINGER, S. 2001. How successful are oncologists in identifying patient distress, perceived social support, and need for psychosocial counselling? Br J Cancer, 84, 179-85.

Velikova, G., Keding, A., Harley, C., Cocks, K., Booth, L., Smith, A. B., Wright, P., Selby, P. J. \& Brown, J. M. 2010. Patients report improvements in continuity of care when quality of life assessments are used routinely in oncology practice: secondary outcomes of a randomised controlled trial. Eur J Cancer, 46, 2381-8.

Webler, T. D., S. and Tuler, S. 2009. Using Q Method to Reveal Social Perspectives in Environmental Research. Available: www.seri- us.org/pubs/Qprimer.pdf [Accessed January 20th 2011]. 
Wells, M. 1998. The hidden experience of radiotherapy to the head and neck: a qualitative study of patients after completion of treatment. J Adv Nurs, 28, 840-8.

Whoqol Group 1993. Whoqol Study Protocol, Geneva, WHO. 


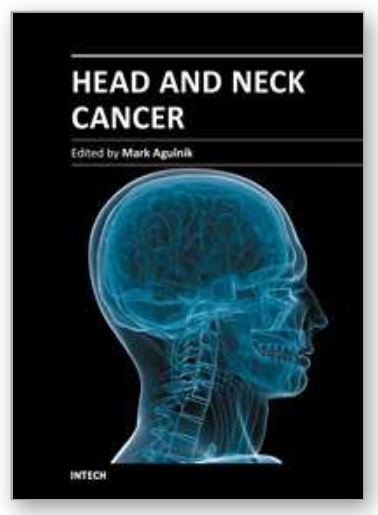

\author{
Head and Neck Cancer \\ Edited by Dr. Mark Agulnik
}

ISBN 978-953-51-0236-6

Hard cover, 440 pages

Publisher InTech

Published online 14, March, 2012

Published in print edition March, 2012

Head and Neck Cancer provides an interesting and comprehensive overview of all aspects of head and neck cancer including overviews of the disease, basic science aspects pertaining to the disease, diagnosis, treatment and outcomes for patients with this disease. The chapters written by world renowned experts cover the entire discipline of head and neck oncology and include discussions of regional disparity is, advances in basic science understanding, advances in her radiotherapy, chemotherapy and targeted agents as well as a focus on reconstruction, prostheses, and aspects of quality of life and health outcomes. The book is designed to be both practical and comprehensive for every physician treating his complex disease.

\title{
How to reference
}

In order to correctly reference this scholarly work, feel free to copy and paste the following:

Kate Reid, Derek Farrell and Carol Dealey (2012). Health Related Quality of Life Questionnaires: Are They Fit for Purpose?, Head and Neck Cancer, Dr. Mark Agulnik (Ed.), ISBN: 978-953-51-0236-6, InTech, Available from: http://www.intechopen.com/books/head-and-neck-cancer/health-related-quality-of-life-questionnairesare-they-fit-for-purpose-

\section{INTECH}

open science | open minds

\section{InTech Europe}

University Campus STeP Ri Slavka Krautzeka 83/A 51000 Rijeka, Croatia Phone: +385 (51) 770447 Fax: +385 (51) 686166 www.intechopen.com

\section{InTech China}

Unit 405, Office Block, Hotel Equatorial Shanghai No.65, Yan An Road (West), Shanghai, 200040, China 中国上海市延安西路65号上海国际贵都大饭店办公楼 405 单元 Phone: +86-21-62489820

Fax: $+86-21-62489821$ 
(C) 2012 The Author(s). Licensee IntechOpen. This is an open access article distributed under the terms of the Creative Commons Attribution 3.0 License, which permits unrestricted use, distribution, and reproduction in any medium, provided the original work is properly cited. 